\section{A Significant Loss in Photosynthetic Activity Associated with the Yellow Vine Syndrome of Cranberry}

\author{
Fan Zhang and Zi Wei \\ Department of Chemistry and Biochemistry, University of Massachusetts \\ Dartmouth, 285 Old Westport Road, North Dartmouth, MA 02747
}

Peter Jeranyama and Carolyn DeMoranville

Cranberry Experimental Station, University of Massachusetts Amherst, 1

State Bog Road, East Wareham, MA 02538

\author{
Harvey J.M. Hou ${ }^{1}$ \\ Department of Chemistry and Biochemistry, University of Massachusetts \\ Dartmouth, 285 Old Westport Road, North Dartmouth, MA 02747
}

Additional index words. yellow vine syndrome, cranberry, chlorophyll, chlorophyll fluorescence, HPLC, photosynthesis

\begin{abstract}
Numerous observations of yellow vine syndrome of cranberry have been reported from commercial cranberry growers. The molecular mechanism resulting in yellow vine syndrome is unknown. We have previously reported on the shading effect as an approach to explore the mechanisms of yellow vine formation and proposed photoinhibition as a possible cause. To compare the photosynthetic performance of yellow vine-affected and normal cranberry leaves, we conducted chlorophyll fluorescence analyses over 1 period of 1 day and 3 weeks, respectively. Both experimental data sets indicated that the maximum quantum efficiency of photosystem II, the size of the quinone pool, the numbers of reaction centers (RCs) per chlorophyll absorption, and the photosynthesis performance index of the yellow vine samples are substantially lower than those of normal cranberry leaves. These results are in line with the data of yellow vine leaves, having $26 \%$ to $28 \%$ less in chlorophyll than the normal leaves as measured by spectrometric and high-performance liquid chromatography analysis. We concluded that yellow vine syndrome is associated with poor photosynthetic activity and is likely becoming a threat for the long-term growth and crop production of cranberries.
\end{abstract}

The American cranberry (Vaccinium macrocarpon) contains antioxidants abundant both in quality and quantity because of its significant flavonoid content and phenolic acids. It is popular as a nutritious food and beverage source and has well-documented health benefits for various human diseases, including cardiovascular disease and cancer (Deyhim et al., 2007; Howell et al., 1998; Kalgaonkar et al., 2010; Lipson et al., 2007; Neto, 2007; Neto et al., 2008; Youdim et al.,

\footnotetext{
Received for publication 7 Mar. 2011. Accepted for publication $24 \mathrm{Apr} .2011$.

The work was supported by grants from the USDA CSREES, the UMass Dartmouth Chancellor's Research Fund, and UMass Dartmouth Cranberry Research Program.

We thank Drs. Catherine Neto, Emmanuel Ojadi, and Donald Boerth for comments to improve the quality of the manuscript. We also thank Lien-Yang Chou, Wanshu He, Xuejing Hou, Ndi Geh, Sean Cederlund, Joy Patel, Robert Mulkern, and Aaron Raposo at UMass Dartmouth for insightful discussions; Jennifer Sicuranza at UMass Cranberry Station for technical assistance; and Mr. Gilmore for allowing us to use his cranberry bog to conduct experiments.

${ }^{1}$ To whom reprint requests should be addressed; e-mail hhou@umassd.edu.
}

2002). Environmental stress plays an important role in the growth and production of agricultural plants. Response mechanisms of plants to stress factors were proposed in the past decade such as nutrition deficiency (Abadia, 1992; Davies and Grossman, 1998; Imsande, 1998), drought stress (Cornic and Massacci, 1996), heat-induced inactivation (Allakhverdiev et al., 2008; Gombos and Murata, 1998; Pshybytko et al., 2008), ultraviolet and visible effects (Kasahara and Wada, 2005; Tevini, 2004), tolerance to salinity (Demetriou et al., 2007; Munns and Tester, 2008), water stress (Bailey-Serres and Voesenek, 2008; Mommer and Visser, 2005; Sack and Holbrook, 2006), and chilling sensitivity (Nishida and Murata, 1996).

The production and quality of cranberries may be affected by long-term or short-term environmental stress such as temperature, humidity, water, nutrient, and light intensity. To produce uniform quality of cranberries, balanced fertilization and irrigation is vital (Savvas et al., 2009). In addition, treatment for storage of cranberries can play a role. The current recommendation for storage of cranberry is 0 to $7{ }^{\circ} \mathrm{C}$ and $75 \%$ to $82 \%$ relative humidity (Forney, 2009). Sunlight is a powerful and abundant energy source, which can be harmful to plants, including cranberry (Bailey and Grossman, 2008; Kramer, 2010; Takahashi and Murata, 2008; Vener, 2007).

Cranberry growers have observed yellow vine syndrome in the cranberry bog under normal light conditions, which produces yellow color along the leaf margins, whereas the area along the vein remains green (Fig. 1). Almost every year numerous reports of yellow vine syndrome in cranberry are received from the cranberry growers in Massachusetts (DeMoranville et al., 2009). Typically the symptoms appear first in the year-old leaves and then move up the stem into the new growth. The most common time for the symptoms to become severe is around or after fruit set when demand for resources in the plants is high. Nutritional imbalance might be associated with yellow vine development in cranberry (DeMoranville et al., 2009). However, fertilizer management is not the cause of the problem. It is possible that nutrient imbalance is secondary to root problems. Additionally, yellow vine syndrome often worsens in bogs with drainage problems, indicating that water stress may be another factor in the formation of yellow vine in cranberries (DeMoranville et al., 2009). Water stress conditions may lead to poor root development. Alternatively, yellow vine symptom might be a result of root rot, viruses, pathogens, or other biological problems. However, the molecular mechanism causing the yellow vine syndrome in cranberries is unknown.

We have previously reported the shading effect on yellow vine syndrome of cranberry to explore the mechanisms of yellow vine formation and proposed a possible role of photoinhibition to cause the yellow vine syndrome in cranberry plants. A complete understanding of the mechanisms of yellow vine syndrome development in cranberry plants may offer an opportunity to minimize its effect. In this work we use bioanalytical methods, including spectrometry, high-performance liquid chromatography (HPLC), and chlorophyll fluorescence kinetics to examine cranberry leaves with yellow vine syndrome and normal cranberry leaves to provide novel insight into the underlying mechanism causing the syndrome.

\section{Materials and Methods}

Cranberry sample preparation. Leaves of cranberry cultivar Stevens were collected from State Bog in East Wareham, MA. Five sets of normal cranberry plant samples (each $\approx 100 \mathrm{~g}$ ) and five sets of yellow vine samples (each $\approx 100 \mathrm{~g}$ ) were harvested from the different areas in the bog, respectively. These samples were quantified immediately or stored at $-80{ }^{\circ} \mathrm{C}$ for later use. To extract the pigments from the cranberry leaves, $\approx 5 \mathrm{~g}$ of leaves were shredded completely at $4{ }^{\circ} \mathrm{C}$ in a blender. The resulting leaf paste mixtures were extracted with $50 \mathrm{~mL}$ of $100 \%$ methanol (Sigma) for $1 \mathrm{~h}$ in the dark at room temperature. The extract solution was immediately analyzed by spectrometric and HPLC methods or stored in the dark at $-80{ }^{\circ} \mathrm{C}$ for later use.

Experimental design and statistical analysis. Chlorophyll (Chl) content in plants can be 
easily determined by extraction using organic solvents followed by spectrometric and HPLC methods (Borrmann et al., 2009; De las Rivas et al., 1989; Porra et al., 1989; Shioi et al., 1983). The difference in chlorophyll between the yellow vine and normal leaves was monitored. Chlorophyll fluorescence analysis is widely used to probe the photosynthetic behaviors of plants in vivo. It will enable us to examine the difference in photosynthetic activity between the normal and yellow vine leaves. For spectrometric and HPLC analysis, three replicated measurements were made and used to calculate the SDS. For chlorophyll fluorescence analysis, five replicated measurements were conducted for determination of photosynthetic parameters and used to calculate SDS. A $t$ test was used to compare the measurement of yellow vine leaves with the measurement of normal cranberry leaves to decide whether they are statistically different (Harries, 2003).

Chlorophyll analysis by ultraviolet-visible absorption spectrometry. The pigment extracts of cranberry leaves were diluted with the extraction solvent to the proper concentration before spectrometric measurement. Typically, $100-\mu \mathrm{L}$ extractions were diluted 1000 times with the extraction solvent methanol. The ultraviolet-visible absorption spectra were recorded with Hewlett Packard 8452A diode array spectrophotometer with a 1-cm light path cuvette. The concentration of Chl $a$ and Chl $b$ was calculated using the equations: $\mathrm{Chl} a=$ $16.29 \mathrm{~A}^{665.2}-8.54 \mathrm{~A}^{652.0}$ and $\mathrm{Chl} b=30.66$ $\mathrm{A}^{652.0}-13.58 \mathrm{~A}^{665.2}$ according to published procedures (Porra et al., 1989), respectively.

Chlorophyll analysis by high-performance liquid chromatography. A reverse-phase HPLC column $(250 \times 4.6 \mathrm{~mm}$, Grace Prevail C18, $5 \mu \mathrm{m})$ with a diode array detector (DAD) (HP 1200 series LC systems; Agilent Inc.) was used for HPLC analysis according to published procedures (De las Rivas et al., 1989). The column was equilibrated with acetonitrile:methanol ( $7: 1$ by v/v, mobile phase A). The mobile phase A was pumped at the flow rate of $1 \mathrm{~mL} \cdot \mathrm{min}^{-1}$ for 2 min immediately after sample injection. Next, a mixture of acetonitrile:methanol:water: ethyl acetate (7:0.96:0.04:2, mobile phase B) was pumped for $1 \mathrm{~min}$. Finally, acetonitrile: methanol:water:ethyl acetate (7:0.96:0.04:8, mobile phase C) was pumped until all the components were eluted. The doubly distilled water was filtered with a HPLC solvent filter and used in HPLC analysis. The detection wavelength was set at $450 \mathrm{~nm}$. The standard solution of Chl $a$ (1.00 ppm in methanol) was prepared using Chl $a$ purchased from Sigma and used for HPLC analysis. The quantitative analysis of $\mathrm{Chl} b$ was conducted using the response factor of Chl $a$. The chromatographic peaks were identified by three different techniques: an internal standard, absorption spectra obtained by the DAD detector, and published HPLC data (De las Rivas et al., 1989).

Chlorophyll fluorescence assay of cranberry leaves in the bog. The Chl fluorescence parameters of cranberry leaves in bogs were determined with portable Pocket PEA Chlorophyll Fluorimeters (Hansatech Instruments Ltd.,
U.K.). Yellow vine syndrome and normal cranberry leaves were collected randomly and used for Chl fluorescence measurements immediately. Typically, five leaves in five different plants located in five different areas in the bog were chosen for the measurements. The in vivo Chl fluorescence parameters were determined after a 10-min dark period in the bog with a cover provided by the equipment. The samples were collected using attached leaves. The data from detached and attached leaves were in agreement within the relative error of $10 \%$ to $15 \%$. The field experiments were carried out once a week for 3 weeks in Sept. to Oct. 2008. The Chl fluorescence data from an average of five replicated measurements was used to calculate the photosynthetic parameters.

\section{Results and Discussion}

Spectrometric and high-performance liquid chromatography analysis. Cranberry leaves with yellow vine syndrome in bogs typically exhibit yellowing along the leaf margins. Chlorophyll content in the plant leaves was easily determined for normal and affected

samples. We anticipated lower Chl content in yellow vine leaves than the normal healthy ones, and this was supported in the analysis of leaf tissue and is shown in Table 1. The content of both Chl $a$ and Chl $b$ was lower as compared with the normal leaves by $\approx 22 \%$ to $24 \%$. The lower content of Chl $a$ and Chl $b$ was confirmed using HPLC analysis (Table 2). The $t$ test showed that the differences in Chl $a$ and $\mathrm{Chl} b$ by spectrometric and HPLC analysis are significant at the $95 \%$ confidence level. This suggests that the yellow vine is the result of altered Chl biosynthesis (Castelfranco, 2007) or Chl degradation (Kramer, 2010; Porra and Scheer, 2001). Another possibility would be that the lower Chl content might be the direct photodamage of Chl by excess light energy, because the Chl molecule in photosystem II is one of the main targets in photoinhibition (Aro et al., 1993; Barber and Andersson, 1992; Telfer and Barber, 1989). There is good evidence that photoinhibition occurs because of damage to the oxygen-evolving complex of photosystem II (PSII) (Hakala et al., 2005; Nishiyama et al., 2006; Wei et al., 2011).

It is interesting to note that although the Chl content was lower in yellow vine leaves, the

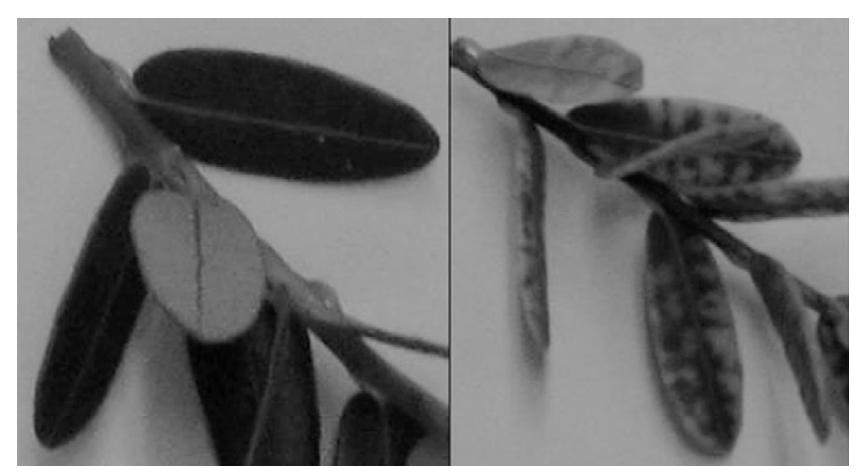

Fig. 1. Images of normal cranberry leaves (left panel) and yellow vine syndrome cranberry leaves (right panel).

Table 1. Spectrometric analytical results of chlorophyll (Chl) $a, \mathrm{Chl} b$, and $\mathrm{Chl} a / \mathrm{Chl} b$ ratio in yellow vine and normal cranberry leaves. ${ }^{2}$

\begin{tabular}{lccc}
\hline & $\begin{array}{c}\text { Normal leaves } \\
\left(\mathrm{mg} \cdot \mathrm{g}^{-1} \text { fresh } \mathrm{wt}\right)\end{array}$ & $\begin{array}{c}\text { Yellow vine syndrome } \\
\text { leaves }\left(\mathrm{mg} \cdot \mathrm{g}^{-1} \text { fresh } \mathrm{wt}\right)\end{array}$ & $\begin{array}{c}\text { Change } \\
(\%)\end{array}$ \\
\hline Chl $a$ & $1.30 \pm 0.09^{\mathrm{y}}$ & $0.99 \pm 0.10$ & 23.8 \\
Chl $b$ & $0.93 \pm 0.06$ & $0.72 \pm 0.09$ & 22.6 \\
Chl $a$ /Chl $b$ ratio & 1.40 & 1.40 & 0 \\
\hline
\end{tabular}

${ }^{2}$ The concentration of $\mathrm{Chl} a$ and $\mathrm{Chl} b$ was determined by measuring absorption spectra of the extracts using organic solvent methanol and calculated using the extinction coefficients and equations published elsewhere (Porra et al., 1989).

${ }^{y}$ The numbers were obtained by average of three independent measurements. The statistic analysis $(t$ test $)$ showed that the differences in $\mathrm{Chl} a$ and $\mathrm{Chl} b$ content are significant at the $95 \%$ confidence level.

Table 2. High-performance liquid chromatography analytical results of chlorophyll (Chl) $a, \mathrm{Chl} b$, and Chl $a / \mathrm{Chl} b$ ratio in yellow vine and normal cranberry leaves. ${ }^{2}$

\begin{tabular}{lccc}
\hline & $\begin{array}{c}\text { Normal leaves } \\
\text { (relative peak area, \%) }\end{array}$ & $\begin{array}{c}\text { Yellow vine syndrome } \\
\text { leaves (relative peak area, \%) }\end{array}$ & $\begin{array}{c}\text { Change } \\
(\%)\end{array}$ \\
\hline Chl $a$ & $42.9 \pm 4.0^{y}$ & $56.4 \pm 5.0$ & 21.8 \\
Chl $b$ & $27.5 \pm 3.0$ & $35.1 \pm 3.0$ & 22.6 \\
Chl $a$ /Chl $b$ ratio & 1.56 & 1.61 & 3.1 \\
\hline
\end{tabular}

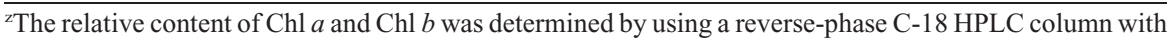
a diode array detector according to the procedures published (De las Rivas et al., 1989).

${ }^{y}$ The numbers were obtained by average of three independent measurements. The statistic analysis $(t$ test) showed that the differences in $\mathrm{Chl} a$ and $\mathrm{Chl} b$ content are significant at the 95\% confidence level. 
ratio of Chl $a$ to $\mathrm{Chl} b$ was almost identical (Tables 1 and 2). We note the $\mathrm{Chl} a / \mathrm{Chl} b$ ratio is slightly different using spectrometric $(\approx 1.4)$ and HPLC analysis $(\approx 1.6)$, which may be the result of the lower accuracy and larger error of the spectrometric data. Alternatively, the response factor of Chl $a$ and Chl $b$ in HPLC profiles may be slightly different. Chlorophyll $a$ is primarily in the reaction centers, and Chl $b$ is predominantly found in light-harvesting complexes (LHCs) in photosynthetic membrane proteins (Blankenship, 2002). The $\mathrm{Chl} a / b$ ratio is practically unchanged, which indicates that both $\mathrm{RC}$ and $\mathrm{LHC}$ are declined. We propose that the lower content of $\mathrm{Chl}$ in yellow vine leaves may be the result of the smaller number of photosynthetic reaction centers and their intact light-harvesting systems.

Chlorophyll fluorescence analysis. The kinetics of the electron transfer steps in photosynthetic reaction centers has been thoroughly investigated over the complete timescale of femtoseconds to many seconds (Brudvig, 2008; Govindjee and Seibert, 2010; Rappaport and Diner, 2008; Renger and Holzwarth, 2005; Seibert and Wasielewski, 2003; van Grondelle and Gobets, 2004). The early electron transfer occurring in PSII revealed by ultrafast spectroscopy can be divided into several steps: 1) absorption of light quanta by antenna to form excited states of pigments; 2) trapping of excitation energy by the primary electron donor $\mathrm{P}_{680}$ in the reaction center on the picosecond time scale; 3) primary charge separation from the singlet excited state of $\mathrm{P}_{680}$ to the primary acceptor Pheo in $\approx 3$ to $20 \mathrm{ps;} 4$ ) stabilization of the separated charges from the radical pair $\mathrm{P}_{680}{ }^{+} \mathrm{Pheo}^{-}$on the acceptor side by electron transfer to $\mathrm{Q}_{\mathrm{A}}$ in $\approx 200 \mathrm{ps}$ and to $\mathrm{Q}_{\mathrm{B}}$ on the hundreds-of- $\mu$ s time scale; and 5) on the donor side, an electron is supplied to reduce $\mathrm{P}_{680}{ }^{+}$ from water through a tyrosine residue $\left(\mathrm{Y}_{\mathrm{Z}}\right)$ and $\mathrm{Mn}_{4} \mathrm{Ca}$ cluster involving a S-state oxygen evolution cycle on the ns- $\mu$ s time scale (Brudvig, 2008; Debus, 1992; Diner and Babcock, 1996; Kok and Radmer, 1976; Rutherford et al., 1992; Tommos and Babcock, 2000).

The fluorescence by $\mathrm{Chl}$ is very sensitive to each step of the PSII electron transfer reactions in vivo. Therefore, $\mathrm{Chl}$ fluorescence is proven to be an intriguing tool and reveals information on plant performance and responses through non-intrusive measurements, especially addressing the effects of plant leaves under environmental stress conditions (Adams and Demmig-Adams, 2004; Baker, 2008; Cavender-Bares and Bazzaz, 2004; Krause and Weis, 1991; Strasser et al., 2004). Figure 2 shows typical Chl fluorescence transients, O-J-I-P curves. When the dark-adapted cranberry samples were illuminated by saturating light, the $\mathrm{Chl}$ fluorescence was increased in three phases: 1) $\mathrm{O} \rightarrow \mathrm{J}$ step is associated with the electron transfer from $\mathrm{P}_{680} *$ to $\mathrm{Q}_{\mathrm{A}}$, and $\mathrm{Mn}_{4} \mathrm{Ca}$ cluster to $\mathrm{P}_{680}{ }^{+}$; 2) $\mathrm{J} \rightarrow \mathrm{I}$ step is related to the electron transfer from $\mathrm{Q}_{\mathrm{A}}$ to $\mathrm{Q}_{\mathrm{B}}$; and 3) $\mathrm{I} \rightarrow \mathrm{P}$ step is the results of the plastoquinone pool reduction (Boisvert et al., 2006; Joly et al., 2010). As shown in Figure 2, the amplitudes in fluorescence (circle symbols in red) for the three steps from the yellow vine

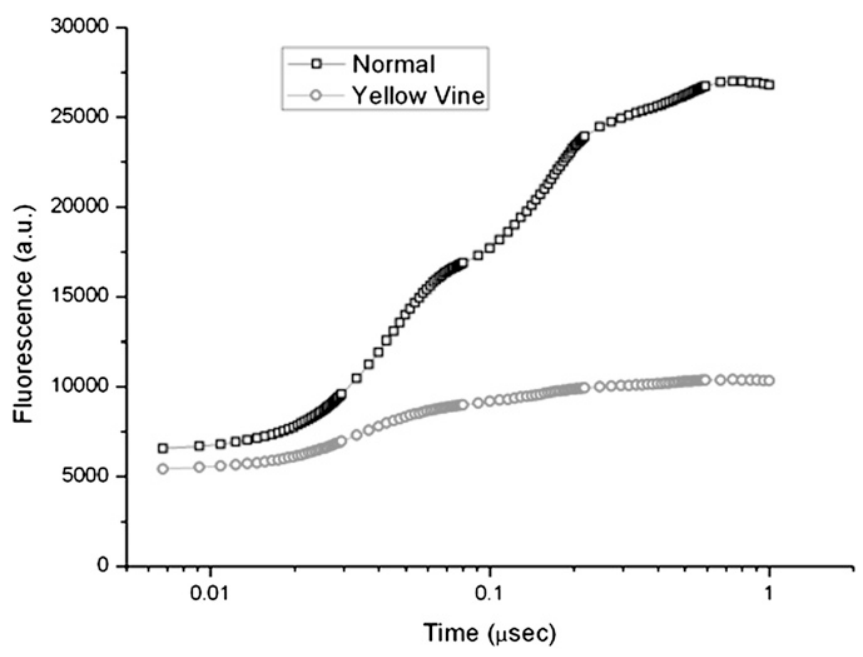

Fig. 2. A representative chlorophyll fluorescence transient curves of normal cranberry leaves (upper, black symbol) and yellow vine syndrome cranberry leaves (lower, gray symbol).

sample were significantly lower than the normal cranberry leaves (square symbols in black), which suggests that the photosynthetic activity in yellow vine samples is dramatically different from the health cranberry leaves.

The interpretation of data in O-I-J-P transient to structural and functional parameters quantifying PSII performance includes initial fluorescence $\left(\mathrm{F}_{\mathrm{o}}\right)$, variable fluorescence $\left(F_{v}\right)$, maximum fluorescence $\left(F_{m}\right)$, total lifetime constant, which is the time to reach the maximum fluorescence, and PSII maximum quantum yield $\left(\mathrm{F}_{\mathrm{v}} / \mathrm{F}_{\mathrm{m}}\right)$ (Strasser et al., 2004). In addition, the "area," which is the quantity of fluorescence area above the transient curve, may represent the size of the PSII quinone pool (Strasser et al., 2004). Figure 3 is a typical spider graph, which summarizes the six Chl fluorescence parameters of cranberry leaves. Five of the six values from the yellow vine cranberry leaves (thin lines in red) were smaller than normal samples (broad lines in black), which indicates a substantial loss in photosynthetic activity resulting from the yellow vine syndrome of cranberry. Similar behavior was observed in camellia leaves with development of an energy pipeline model of the photosynthetic apparatus (Kruger et al., 1997; Toth Szilvia et al., 2007). In contrast, the total lifetime constant of PSII in both samples is nearly identical, implying an intact photosynthetic electron transfer in both leaves. This is agreeable with the unchanged organization of photosynthetic machinery judged by the spectrometric and HPLC data of the Chl $a$ / Chl $b$ ratio.

Table 3 lists the four Chl fluorescence parameters of the yellow vine syndrome and normal cranberry leaves. In addition to $\mathrm{F}_{\mathrm{v}} /$ $\mathrm{F}_{\mathrm{m}}$, "area," the number of RC per chlorophyll absorption (RC/ABS), we calculate the photosynthesis performance index (PI value), which is defined as an indication of a driving force of the primary photosynthetic reaction (Srivastava et al., 1999; Strasser et al., 2004). The PSII maximum quantum yield was decreased by $28 \%$, which is similar to the level of Chl $a$ and $\mathrm{Chl} b(\approx 25 \%)$. We conclude that

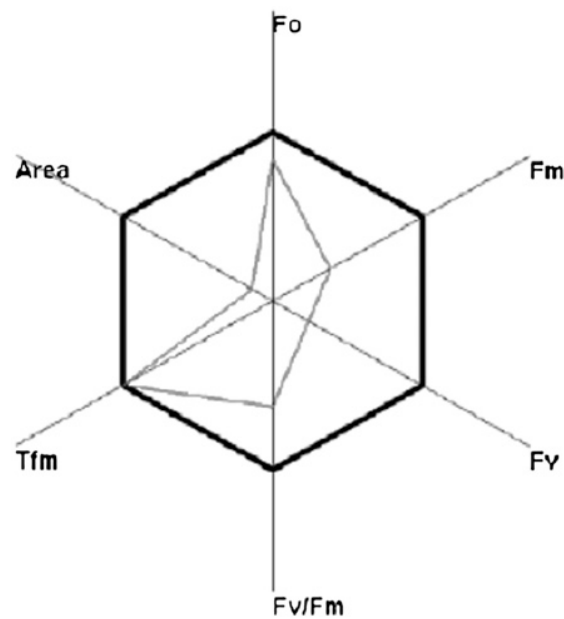

Fig. 3. A typical spider graph of cranberry leaves Black thick lines stands for the normal leaves and gray thin lines stands for the yellow vine samples.

Table 3. Relative chlorophyll fluorescence parameters of yellow vine syndrome and normal cranberry leaves. $^{\mathrm{z}}$

\begin{tabular}{ccccc}
\hline & $\mathrm{F}_{\mathrm{v}} / \mathrm{F}_{\mathrm{m}}$ & Area & $\mathrm{RC} / \mathrm{ABS}$ & $\mathrm{PI}$ \\
\hline Normal & $100 \pm 5^{\mathrm{y}}$ & $100 \pm 15$ & $100 \pm 8$ & $100 \pm 25$
\end{tabular}

leave

Yellow $\quad 72 \pm 4 \quad 40 \pm 6 \quad 43 \pm 5 \quad 11 \pm 3$

vine

${ }^{\mathrm{z}} \mathrm{F}_{\mathrm{v}} / \mathrm{F}_{\mathrm{m}}$ is the maximum quantum yield of photosystem II (PSII); "area" represents the size of quinone pool in PSII; RC/ABS stands for the numbers of photosynthetic reaction center per chlorophyll absorption; PI is the photosynthetic performance index, which is the overall driving force of photosynthetic reaction.

y The values were obtained by average of five independent measurements. The statistic analysis ( $t$ test) showed that the differences in these four parameters are significant at the $95 \%$ confidence level.

the numbers of PSII containing RCs and lightharvesting proteins in yellow vine leaves may be lower than that of normal leaves by $25 \%$ to $30 \%$. The size of the quinone pool and the 
number of RCs per Chl absorption in yellow vine sample were decreased by $57 \%$ to $60 \%$. The $t$ test showed that the differences in $\mathrm{F}_{\mathrm{v}} / \mathrm{F}_{\mathrm{m}}$, area, $\mathrm{RC} / \mathrm{ABS}$, and PI are significant at the 95\% confidence level. The discrepancy between these numbers and $F_{v} / F_{m}$ may be the result of a substantial number of inactive PSII in yellow vine leaves. The content of Chl $a$ and $\mathrm{Chl} b$ is an extrinsic quality and $\mathrm{F}_{\mathrm{v}} / \mathrm{F}_{\mathrm{m}}$ is an intrinsic property. The $\mathrm{F}_{\mathrm{v}} / \mathrm{F}_{\mathrm{m}}$ only inform one about how intact centers are performing, not how many there are. Our $F_{v} / F_{m}$ data could be the result of the decrease in the quinone:PSII ratio. In addition, the much smaller size of the quinone pool will imply the vulnerability and sensitivity of yellow vine to other environmental stress factors. This is supported by the observation that water stress significantly worsens the symptom in the cranberry bog (DeMoranville, 2006; DeMoranville and Lampinen, 1999). The PI value of yellow vine leaves is almost completely diminished with a loss of $\approx 90 \%$. This suggests that the impairment and destruction of the photosynthetic apparatus in yellow vine syndrome of cranberry leaves is multitargeted and complex.

To monitor the photosynthetic behavior of yellow vine leaves in cranberry bogs, we conducted $\mathrm{Chl}$ fluorescence measurements on yellow vine syndrome leaves over a period of 3 weeks in Figure 4 and of $1 \mathrm{~d}$ in Figure 5. As shown in Figure 4, the three quantitiesmaximum quantum yield, size of quinone pool, and photosynthesis performance index - in the yellow vine samples were consistently smaller than the normal leaves over the entire 3 weeks. Similar trends were obtained in the 1-d experiment in Figure 5. This observation confirms the previous experimental data and strongly supports the idea that yellow vine syndrome reduces the photosynthetic activity possibly by inhibiting and degradating multiple protein complexes including decreasing the numbers of PSII complexes.

We noted that the variation and error of the maximum quantum yield of PSII over 3 weeks were rather large (relative SD of 19\%) in the case of yellow vine samples (Fig. 4). In contrast, the parameter over a period of 1 d showed relatively small experimental error (relative SD of 5\%) in Figure 5. This may suggest that the photosynthetic apparatus in yellow vine syndrome is more vulnerable and sensitive to experimental conditions such as changes in temperature, water level, nutrition, humidity, herbicide, light intensity, age of leaves, and disease problems. Alternatively, the variation and large errors may be the result of the sampling of Chl fluorescence experiments, although the data were an average of five independent measurements. However, additional experimental evidence is required to distinguish these possibilities. For example, the effects of temperature, $\mathrm{pH}$, and nutrition on the photosynthetic activity of yellow vine syndrome may support or disprove these hypotheses.

Molecular mechanisms of yellow vine syndrome formation. It is hypothesized that the yellow vine symptoms may be caused by nutritional imbalance and water stress

\section{A}
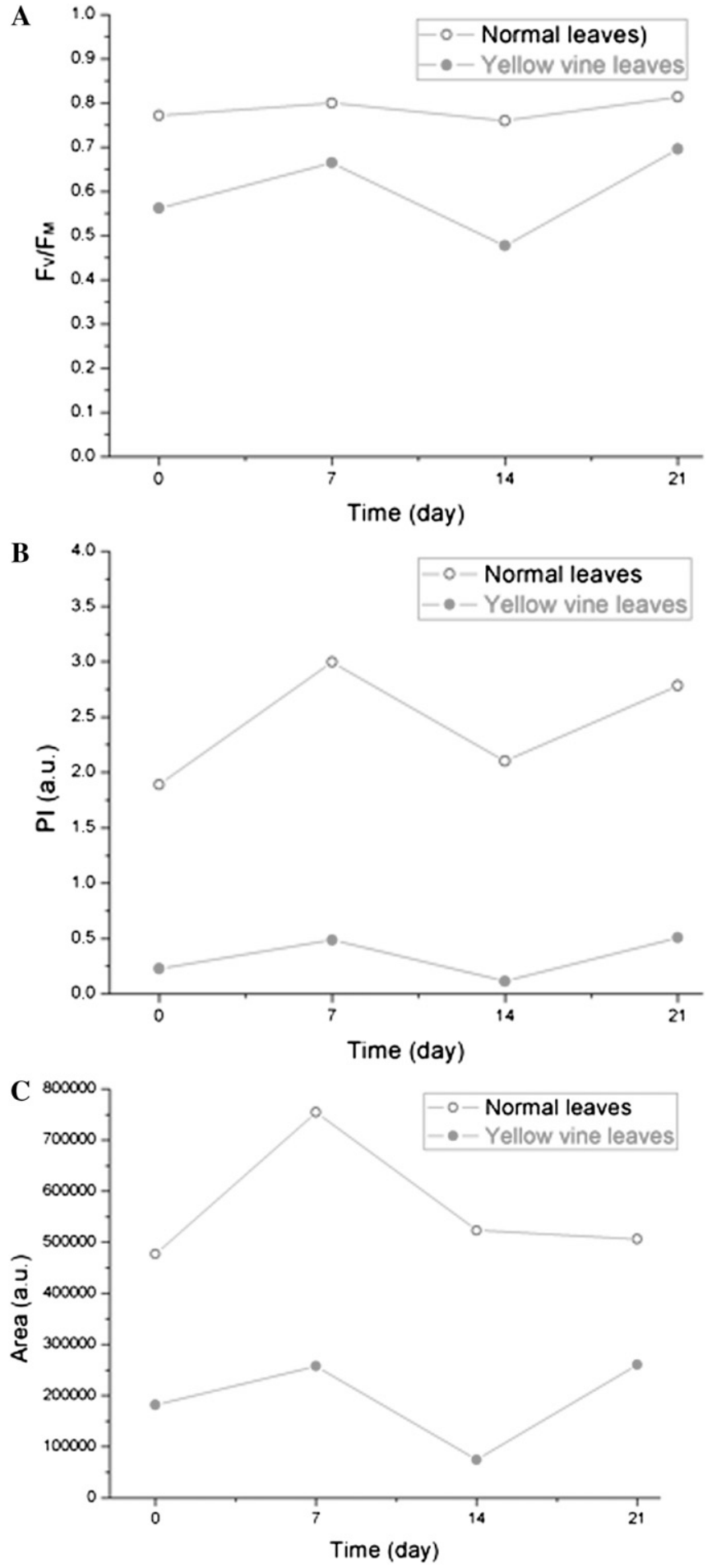

Fig. 4. The chlorophyll fluorescence parameters obtained during a period of 3 weeks. (Upper panel) Photosystem II (PSII) quantum efficiency $\left(\mathrm{F}_{\mathrm{v}} / \mathrm{F}_{\mathrm{m}}\right)$; (midpanel) photosynthesis performance index (PI); (lower panel) quinone pool size (area). The relative sDs are $5 \%$ in $\mathrm{F}_{\mathrm{v}} / \mathrm{F}_{\mathrm{m}}, 15 \%$ in area, and $25 \%$ in PI, respectively.

(DeMoranville et al., 2009). The effect of shade treatment on yellow vine syndrome in cranberry bogs revealed that the shading of cranberry plants appears to reduce the syndrome by improving the photosynthetic activity and increasing the Chl content (Wei et al., 2010). The yellow vine leaves were associated with $11 \% \pm 5 \%$ and $14 \% \pm 5 \%$ increase in $\mathrm{Chl}$ $a / \mathrm{Chl} b$ ratio after shading, respectively. The electron transport efficiency in PSII and the size of the quinone pool are increased. In addition, the overall photosynthesis performance index is drastically improved by shading. These results suggest that the shade effect will increase the numbers of PSII in the cells of yellow vine cranberry leaves. Because PSII is the main target of photoinhibition, we suggest a possible role of 

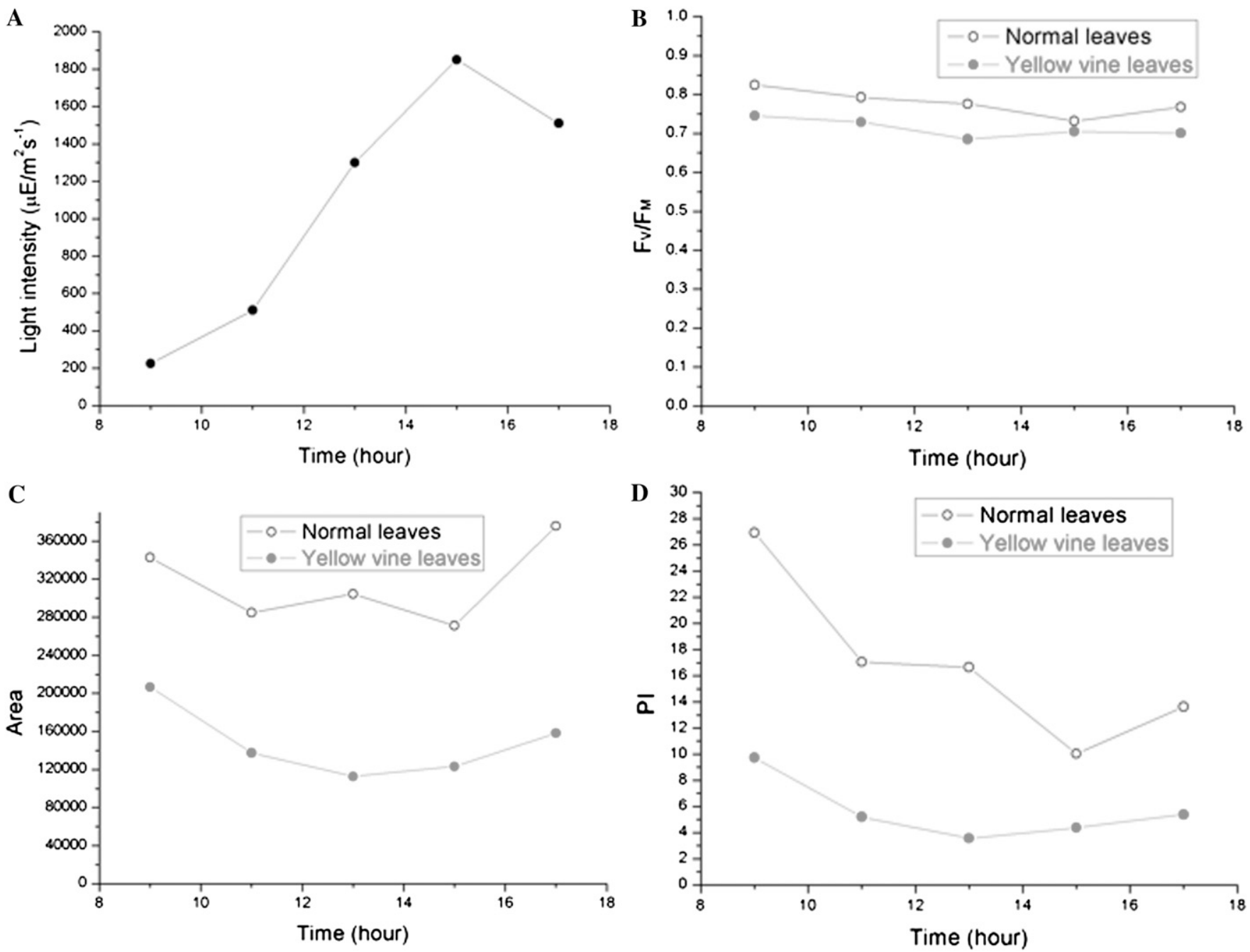

Fig. 5. The chlorophyll fluorescence parameters during a period of $1 \mathrm{~d}$. (Upper left panel) Light intensity during daytime; (upper right panel) photosystem II (PSII) quantum efficiency $\left(\mathrm{F}_{\mathrm{v}} / \mathrm{F}_{\mathrm{m}}\right)$; (lower left panel) quinone pool size (area); (lower right panel) photosynthesis performance index (PI). The relative sDs are 5\% in $\mathrm{F}_{\mathrm{v}} / \mathrm{F}_{\mathrm{m}}, 15 \%$ in area, and $25 \%$ in PI, respectively.

photoinhibition is associated with the yellow vine syndrome in cranberry plants.

Yellow vine formation is likely the result of multiple factors. It is reported that the environmental stress may enhance the photoinhibitory effect on photosynthetic machineries (Takahashi and Murata, 2008). We propose that the combination of photoinhibition, water stress, and nutritional imbalance may cause the yellow vine syndrome of cranberries. Based on our experimental data and previous reports, yellow vine syndrome is likely a result of the decrease in the steady concentration and activity of PSII. We proposed a possible model to explain yellow vine syndrome of cranberry. Nutritional imbalance, water stress, or photodamage results in the formation of fewer PSII centers and this phenomenon results in yellow vine syndrome. Chlorophyll biosynthesis may be inhibited and negatively regulated or degradation of Chl may be activated and positively regulated. Alternatively, increased degradation of D1 could also result in yellow vine syndrome. Our data cannot distinguish between these two possibilities.
Concluding remarks. We investigated the molecular mechanisms of yellow vine formation by spectrometric, HPLC, and Chl fluorescence analysis. The performance of yellow vine and normal cranberry leaves by $\mathrm{Chl}$ fluorescence analysis over 1 period of $1 \mathrm{~d}$ and 3 weeks, respectively, indicated that the photosynthetic parameters of the yellow vine samples are substantially lower than those of the normal cranberry leaves. Spectrometric and HPLC analyses revealed that yellow vine leaves contained $26 \%$ to $28 \%$ less Chl than normal cranberry leaves. These data sets demonstrated that yellow vine syndrome is associated with a poor photosynthetic activity and is problematic for the long-term growth and crop production of cranberries.

The recovery experiments may provide further insight into the mechanisms of yellow vine syndrome development in cranberry bogs and offer an opportunity to solve the problem. Recent recovery of photoinhibited plant leaves was examined, and PSII mobility in thylakoid membranes may play a key role (Oguchi et al., 2008). We plan to conduct experiments on the recovery from the syn- drome to establish optimized experimental conditions.

\section{Literature Cited}

Abadia, J. 1992. Leaf responses to iron deficiency: A review. J. Plant Nutr. 15:1699-1713.

Adams, W.W. I.I.I. and B. Demmig-Adams. 2004. Chlorophyll fluorescence as a tool to monitor plant response to the environment. Advances in Photosynthesis and Respiration. 19:583-604.

Allakhverdiev, S.I., V.D. Kreslavski, V.V. Klimov, D.A. Los, R. Carpentier, and P. Mohanty. 2008. Heat stress: An overview of molecular responses in photosynthesis. Photosynth. Res. 98:541-550.

Aro, E.M., I. Virgin, and B. Andersson. 1993. Photoinhibition of photosystem II. Inactivation, protein damage and turnover. Biochim. Biophys. Acta. 1143:113-134

Bailey, S. and A. Grossman. 2008. Photoprotection in cyanobacteria: Regulation of light harvesting. Photochem. Photobiol. 84:1410-1420.

Bailey-Serres, J. and L.A.C.J. Voesenek. 2008. Flooding stress: Acclimations and genetic diversity. Annu. Rev. Plant Biol. 59:313-339.

Baker, N.R. 2008. Chlorophyll fluorescence: A probe of photosynthesis in vivo. Annu. Rev. Plant Biol. 59:89-113. 
Barber, J. and B. Andersson. 1992. Too much of a good thing: Light can be bad for photosynthesis. Trends Biochem. Sci. 17:61-66.

Blankenship, R.E. 2002. Molecular mechanisms of photosynthesis. Blackwell Science.

Boisvert, S., D. Joly, and R. Carpentier. 2006. Quantitative analysis of the experimental O-J-I-P chlorophyll fluorescence induction kinetics. Apparent activation energy and origin of each kinetic step. FEBS J. 273:4770-4777.

Borrmann, D., J. Castelhano de Andrade, and U.M. Lanfer-Marquez. 2009. Chlorophyll degradation and formation of colorless chlorophyll derivatives during soybean (Glycine max L. Merill) seed maturation. J. Agr. Food Chem. 57:2030-2034.

Brudvig, G.W. 2008. Water oxidation chemistry of photosystem II. Philos. Trans. R. Soc. B. 363:1211-1219.

Castelfranco, P.A. 2007. Studies on chlorophyll biosynthesis and other things. Photosynth. Res. 91:25-36.

Cavender-Bares, J. and F.A. Bazzaz. 2004. From leaves to ecosystems: Using chlorophyll fluorescence to assess photosynthesis and plant function in ecological studies. Advances in Photosynthesis and Respiration. 19:737-755.

Cornic, G. and A. Massacci. 1996. Leaf photosynthesis under drought stress. Advances in Photosynthesis. 5:347-366.

Davies, J.P. and A.R. Grossman. 1998. Responses to deficiencies in macronutrients. Advances in Photosynthesis. 7:613-635.

De las Rivas, J., A. Abadia, and J. Abadia. 1989. A new reversed-phase HPLC method resolving all major higher plant photosynthetic pigments. Plant Physiol. 91:190-192.

Debus, R.J. 1992. The manganese and calcium ions of photosynthetic oxygen evolution. Biochim. Biophys. Acta. Bioenerg. 1102:269-352.

Demetriou, G., C. Neonaki, E. Navakoudis, and K. Kotzabasis. 2007. Salt stress impact on the molecular structure and function of the photosynthetic apparatus - The protective role of polyamines. Biochimica et Biophysica Acta. Bioenergetics. 1767:272-280.

DeMoranville, C. 2006. Cranberry best management practice adoption and conservation farm planning in Massachusetts. HortTechnology 16:393-397.

DeMoranville, C., B. Howes, D. Schlezinger, and D. White. 2009. Cranberry phosphorus management: How changes in practice can reduce output in drainage water. Acta Hort. 810:633640.

DeMoranville, C. and B. Lampinen. 1999. University of Massachusetts Extension's Cranberry Station Newsletter. p. 2-3.

Deyhim, F., B.S. Patil, A. Villarreal, E. Lopez, K. Garcia, R. Rios, C. Garcia, C. Gonzales, and K. Mandadi. 2007. Cranberry juice increases antioxidant status without affecting cholesterol homeostasis in orchidectomized rats. J. Med. Food. 10:49-53.

Diner, B.A. and G.T. Babcock. 1996. Structure, dynamics, and energy conversion efficiency in photosystem II. Advances in Photosynthesis. 4:213-247.

Forney, C.F. 2009. Postharvest issues in blueberry and cranberry and methods to improve marketlife. Acta Hort. 810:785-798.

Gombos, Z. and N. Murata. 1998. Genetic engineering of the unsaturation of membrane glycerolipid: Effects on the ability of the photosynthetic machinery to tolerate temperature stress. Advances in Photosynthesis. 6:249-262.

Govindjee and M. Seibert. 2010. Picosecond spectroscopy of the isolated reaction centers from the photosystems of oxygenic photosynthesisTen years (1987-1997) fun. Photosynth. Res. 103:1-6.

Hakala, M., I. Tuominen, M. Keranen, T. Tyystjarvi, and E. Tyystjarvi. 2005. Evidence for the role of the oxygen-evolving manganese complex in photoinhibition of photosystem II. Biochim. Biophys. Acta. 1706:68-80.

Harries, D.C. 2003. Quantitative chemical analysis. 6th Ed. Freeman, p. 69-75.

Howell, A., N. Vorsa, A. Der-Petrossian, and L. Foo. 1998. Inhibition of the adherence of Pfimbriated Escherichia coli to uroepithelial-cell surfaces by proanthocyanidin extracts from cranberries. N. Engl. J. Med. 339:1085-1086.

Imsande, J. 1998. Iron, sulfur, and chlorophyll deficiencies: A need for an integrative approach in plant physiology. Physiol. Plant. 103:139-144.

Joly, D., E. Jemaa, and R. Carpentier. 2010. Redox state of the photosynthetic electron transport chain in wild-type and mutant leaves of Arabidopsis thaliana: Impact on photosystem II fluorescence. J. Photochem. Photobiol. B 98: 180-187.

Kalgaonkar, S., H.B. Gross, W. Yokoyama, and C.L. Keen. 2010. Effects of a flavonol-rich diet on select cardiovascular parameters in a golden Syrian hamster model. J. Med. Food. 13:108115.

Kasahara, M. and M. Wada. 2005. Chloroplast avoidance movement. Annual Plant Reviews. 13:267-282

Kok, B. and R. Radmer. 1976. Mechanisms in photosynthesis. ACS Monograph. 172:172220.

Kramer, D.M. 2010. The photonic smart grid of the chloroplast in action. Proc. Natl. Acad. Sci. USA. 107:2729-2730.

Krause, G.H. and E. Weis. 1991. Chlorophyll fluorescence and photosynthesis: The basics. Annu. Rev. Plant Physiol. Plant Mol. Biol. 42: 313-349.

Kruger, G.H.J., M. Tsimilli-Michael, and R.J. Strasser. 1997. Light stress provokes plastic and elastic modifications in structure and function of photosystem II in camellia leaves. Physiol. Plant. 101:265-277.

Lipson, S.M., P. Cohen, J. Zhou, A. Burdowski, and G. Stotzky. 2007. Cranberry cocktail juice, cranberry concentrates, and proanthocyanidins reduce reovirus infectivity titers in African green monkey kidney epithelial cell cultures. Mol. Nutr. Food Res. 51:752-758.

Mommer, L. and E.J.W. Visser. 2005. Underwater photosynthesis in flooded terrestrial plants: A matter of leaf plasticity. Annals of Botany (Oxford, United Kingdom) 96:581-589.

Munns, R. and M. Tester. 2008. Mechanisms of salinity tolerance. Annu. Rev. Plant Biol. 59: 651-681.

Neto, C.C. 2007. Cranberry and its phytochemicals: A review of in vitro anticancer studies. J. Nutr. 137:186S-193S.

Neto, C.C., W. Amoroso Jon, and M. Liberty Anne. 2008. Anticancer activities of cranberry phytochemicals: An update. Mol. Nutr. Food Res. 52(suppl 1):S18-S27.

Nishida, I. and N. Murata. 1996. Chilling sensitivity in plants and cyanobacteria: The crucial contribution of membrane lipids. Annu. Rev. Plant Physiol. Plant Mol. Biol. 47:541568.

Nishiyama, Y., S.I. Allakhverdiev, and N. Murata. 2006. A new paradigm for the action of reactive oxygen species in the photoinhibition of photosystem II. Biochim. Biophys. Acta. 1757: 742-749.
Oguchi, R., H. Jia, J. Barber, and W.S. Chow. 2008. Recovery of photoinactivated photosystem II in leaves: Retardation due to restricted mobility of photosystem II in the thylakoid membrane. Photosynth. Res. 98:621-629.

Porra, R.J. and H. Scheer. 2001. 180 and mass spectrometry in chlorophyll research: Derivation and loss of oxygen atoms at the periphery of the chlorophyll macrocycle during biosynthesis, degradation and adaptation. Photosynth. Res. 66:159-175.

Porra, R.J., W.A. Thompson, and P.E. Kriedemann. 1989. Determination of accurate extinction coefficients and simultaneous equations for assaying chlorophylls a and $\mathrm{b}$ extracted with four different solvents: Verification of the concentration of chlorophyll standards by atomic absorption spectroscopy. Biochimica et Biophysica Acta. Bioenergetics. 975:384394.

Pshybytko, N.L., J. Kruk, L.F. Kabashnikova, and K. Strzalka. 2008. Function of plastoquinone in heat stress reactions of plants. Biochim. Biophys. Acta. Bioenerg. 1777: 1393-1399.

Rappaport, F. and B.A. Diner. 2008. Primary photochemistry and energetics leading to the oxidation of the $\mathrm{Mn} 4 \mathrm{Ca}$ cluster and to the evolution of molecular oxygen in photosystem II. Coord. Chem. Rev. 252:259-272.

Renger, G. and A.R. Holzwarth. 2005. Primary electron transfer. Adv. Photosynth. Respir. 22:139-175.

Rutherford, A.W., J.L. Zimmermann, and A. Boussac. 1992. Oxygen evolution. Topics in Photosynthesis. 11:179-229.

Sack, L. and N.M. Holbrook. 2006. Leaf hydraulics. Annu. Rev. Plant Biol. 57:361-381.

Savvas, D., C. Olympios, and H.C. Passam. 2009. Management of nutrition and irrigation in soilgrown and soilless cultivations in mild-winter climates: Problems, constraints and trends in the Mediterranean region. Acta Hort. 807:415426.

Seibert, M. and M.R. Wasielewski. 2003. The isolated photosystem II reaction center: First attempts to directly measure the kinetics of primary charge separation. Photosynth. Res. 76:263-268.

Shioi, Y., R. Fukae, and T. Sasa. 1983. Chlorophyll analysis by high-performance liquid chromatography. Biochimica et Biophysica Acta. Bioenergetics. 722:72-79.

Srivastava, A., R.J. Strasser, and Govindjee. 1999. Greening of peas: Parallel measurements of $77 \mathrm{~K}$ emission spectra, OJIP chlorophyll a fluorescence transient, period four oscillation of the initial fluorescence level, delayed light emission, and P700. Photosynthetica 37:365-392.

Strasser, R.J., M. Tsimilli-Michael, and A. Srivastava. 2004. Analysis of the chlorophyll a fluorescence transient. Adv. Photosynth. Respir. 19: 321-362.

Takahashi, S. and N. Murata. 2008. How do environmental stresses accelerate photoinhibition? Trends Plant Sci. 13:178-182.

Telfer, A. and J. Barber. 1989. Evidence for the photoinduced oxidation of the primary electron donor P680 in the isolated photosystem II reaction center. FEBS Lett. 246:223228.

Tevini, M. 2004. Plant responses to ultraviolet radiation stress. Advances in Photosynthesis and Respiration. 19:605-621.

Tommos, C. and G.T. Babcock. 2000. Proton and hydrogen currents in photosynthetic water 
oxidation. Biochimica et Biophysica Acta. Bioenergetics. 1458:199-219.

Toth Szilvia, Z., G. Schansker, G. Garab, and J. Strasser Reto. 2007. Photosynthetic electron transport activity in heat-treated barley leaves: The role of internal alternative electron donors to photosystem II. Biochim. Biophys. Acta. 1767:295-305.

van Grondelle, R. and B. Gobets. 2004. Transfer and trapping of excitations in plant photosystems. Advances in Photosynthesis and Respiration 19:107-132.
Vener, A.V. 2007. Environmentally modulated phosphorylation and dynamics of proteins in photosynthetic membranes. Biochimica et Biophysica Acta. Bioenergetics 1767:449457.

Wei, Z., C. Cady, G.W. Brudvig, and H.J.M. Hou. 2011. Photodamage of a Mn(III/IV)-oxo mix valence compound and photosystem II complexes: Evidence that high-valent manganese species is responsible for UV-induced photodamage of oxygen evolving complex in photo- system II. J. Photochem. Photobiol. B: Biol. doi: 10.1016/j.jphotobiol.2011.01.017.

Wei, Z., P. Jeranyama, F. Zhang, C. DeMoranville, and H.J.M. Hou. 2010. Probing the mechanisms of the yellow vine syndrome development in cranberry: Shade effect. HortScience 45:1345-1348.

Youdim, K.A., J. McDonald, W. Kalt, and J.A Joseph. 2002. Potential role of dietary flavonoids in reducing microvascular endothelium vulnerability to oxidative and inflammatory insults. J. Nutr. Biochem. 13:282-288. 